\title{
تقييم فاعلية برنامج التدريب الميداني بالتربية الخاصة من وجهة نظر الطلبة في جامعة جدارا
}

\author{
علي محممد الصهمادي \\ قسم التربية الخاصية- كلية العلوم التربوية- جامعهاه جدارا- الأردن \\ alismadi_58@yahoo.com
}

DOI: https://doi.org/DOI:10.31559/EPS2020.8.2.12

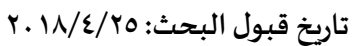

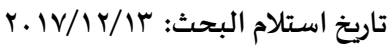

هدفت الدراسة إلى تقييم فاعلية برنامج التدريب الميداني للطلبة الخريجين في تخصص التربية الخاصة من وجهاة نظر الطلبة انفسهم، تكون

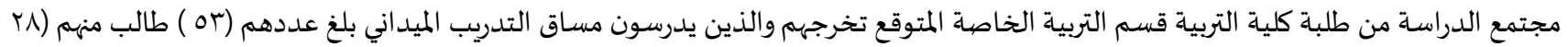

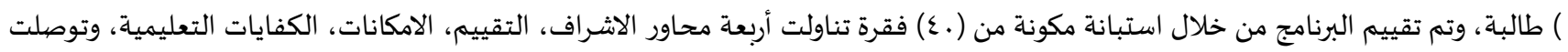

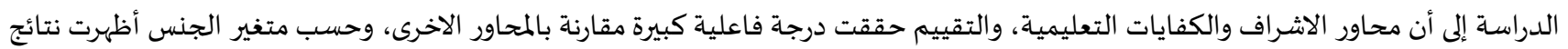

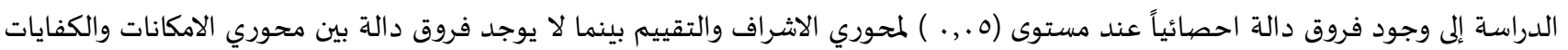

الكلمات المفتاحية: التدريب الميداني؛ التربية الخاصة؛ الطلبة. (c) (1)

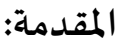

تعتبر عملية إعداد المعلم من الأهداف الأساسية التي تقدمها البرامج التربوية في الجامعات لطلبة خريجي العلوم التربوية، وإعداد معلم التربية

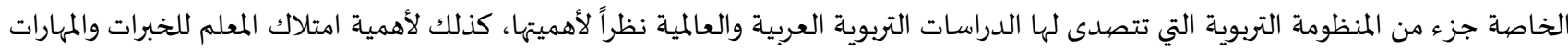
والمعارف التربوية التي يتلقاها الطالب ضمن مساقات دراسية جميعها تدعم قدرة الطالب على تنفيذ العملية التعليمية بكفاءة تساعده وبأعلى

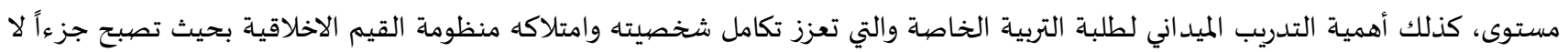
يتجزأ من كيانه المني ومشاعره وقيمه واتجاهـ الشخصي نحو الاشخاص المعوقين. وبسب اختلاف الطلبة المعوقين في مراكز ومؤسسات التربية

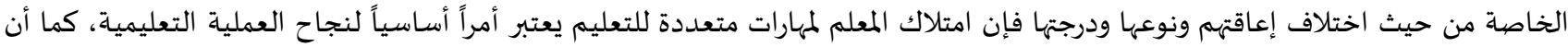

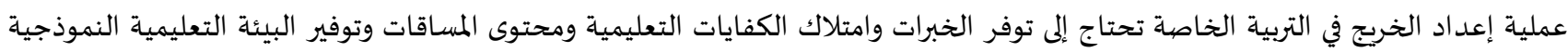
والاشراف والعديد من العوامل كلها لتخريج معلم مؤهل لتنفيذ هذه المهمة .كما أن كفاءة خريج تخصص التهاتيه التربية الخاصة تعتبر مؤشر هام على تطور

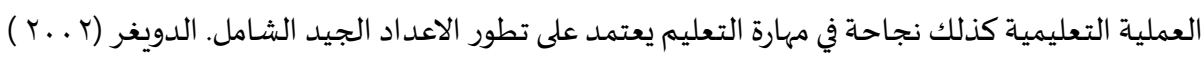

مشكلة الدراسـة:

تساعد الدراسة الحالية في تحديد أوجه القصور والضعف في برنامج التدريب الميداني لطلبة التربية الخاصة في جامعهه جدارا، كما وتقدم نتائج الدراسة الفائدة للمشرفين على وضع وتنفيذ برنامج التدريب الميداني بالجامعة حيث تتمثل مشكلة الدراسة في التعرف على فاعلية برنامج التدريب الميداني من وجها نظر الطلبة والذي يطبقه الطلبة الخريجين في تخصص وضئ التربية الخاصة قبل قلئ تخرجهم ويتم ذلك من خلال الاجابة على التساؤلات التالية:

السؤال الأول: "ما مدى فاعلية برنامج التدريب الميداني للتربية الخاصة في جامعة جدارا من وجهة نظر طلبة الخريجين في المجالات التالية

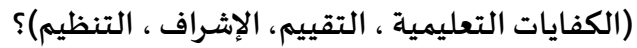

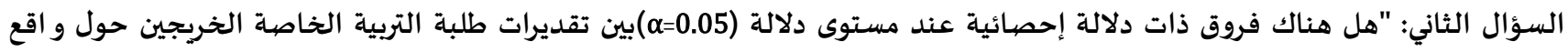

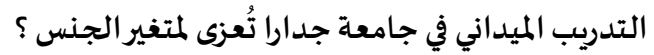


1. تبحث الدراسـة الحالية في تقويم محتوى برنامج التدريب الميداني المقدمة لطلبة التربية الخاصية. r r. تحديد نقاط القوة والضعف في برنامج التدريب الميداني لطلبة التربية الخاصة. r. توفر قاعدة لتحديد مستوى ونوعية البرامج الواجب تقديمها لطلبة التربية الخاصة في التدريب الميداني.

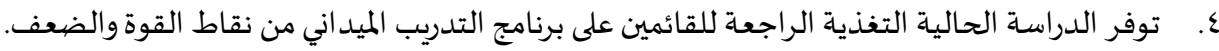
0. لم يتم اجراء تقييم لبرنامج التدريب الميداني في كلية العلوم التربوية او من قبل قسم التربية الخاصية بالجامعاية.

الاهمية العملية:

ا. الاسهام في تطوير برامج التدريب الميداني وتنفيذها وتقويمها. r r توفير برامج متطورة لرفع مستوى التدريب الميداني لطلبة التربية الخاصية. r. توفر الدراسـة اداوات للتعرف على ايجابيات وسلبيات برنامج التدريب الميداني. حدود الدراسـة: الحدود الموضوعية: اقتصرت هذه الدراسة على التعرف على فاعلية برنامج التدريب الميداني للتربية الخاصة ضمن المحاور التالية( الكفايات التعليمية، الاشراف، التقييم، التنظيم ). الحدود البشرية: الطلبة الخريجين في كلية العلوم التربوية - قسم التربية الخاصية .

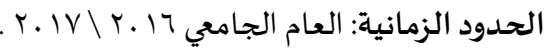
الحدود المكانية : جامعة جدارا.

مصطلحات الدراسة:

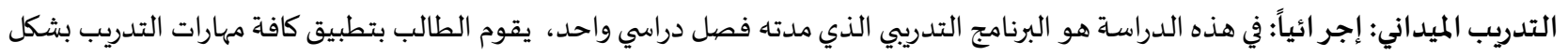

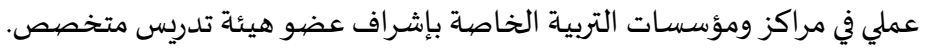

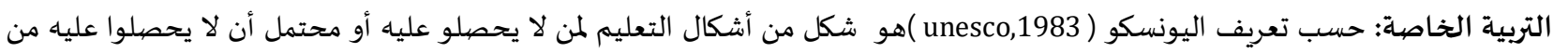
خلال نظم التعليم المتاحة بهدف الوصول بهم إلى مستويات تعليمية واجتماعية ملائمة لعمرهم. ه الطلبة الخريجين: إجر ائياً: في حدود هذه الدراسة هم الطلبة الذين أههوا اكثر من تسعة وتسعون ساعة دراسية في تخصص التربية الخاصة ومسجلون في مساق التدريب الميداني .

الإطار النظري:

لما كان للتدريب الميداني من أهمية بالغة في إعداد المعلمين وتوظيف الجوانب والمعارف النظرية التي يتلقاها هؤلاء الطلاب في الفصول الدراسية

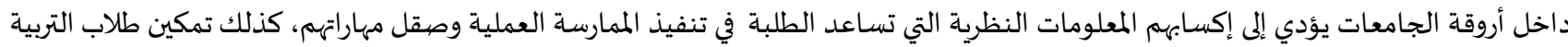

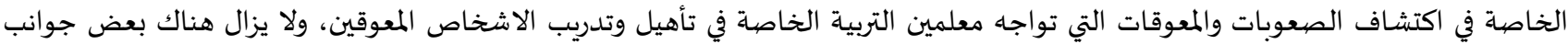
القصور في إعداد طلاب التربية الخاصة حيث لم يحظى التدريب الميداني الاهتمام المطلوب في تحضير وإعداد الطالب للممارسة فيما بعد المات حيث التركيز على الجانب النظري أخذ جل اهتمام المختصين من الأكاديميين وأساتذة الجامعات والممارسين.

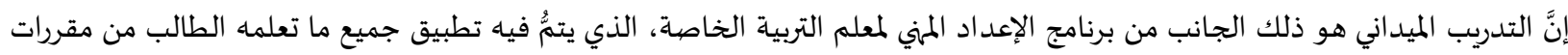
نظرياة، وتزويده بالاتجاهات الإيجابية نحو المهنة من جهة، ونحو مهارات التعليم الخاصة بالفئة التي سوف يتعامل معها من جهة ثانية.

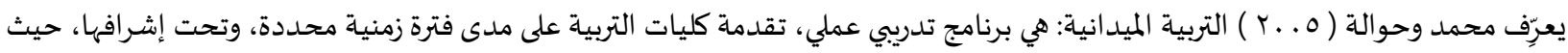
يهدف هذا البرنامج إلى إتاحة الفرصة للطلاب المعلمين لتطبيق ما تعلموه من معلومات وأفكار ومفاهيم نظرية، تطبيقاً عملياً في أثناء قيامهم بمهام

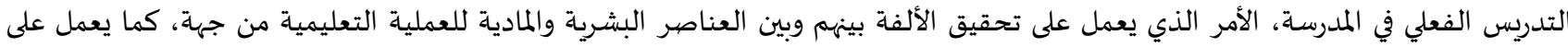

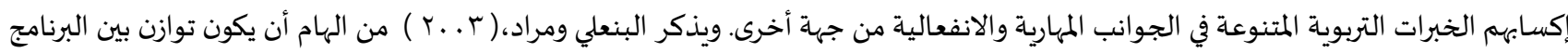

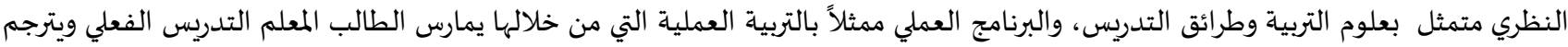
المعارف النظرية من خلال الممارسة العملية. 
وحول ضرورة افساح المجال للطالب المعلم يذكر حمد (V. . . أ أنه من الضيروري فسح المجال أمام الطالب من خلال تصميم بطاقات تقويم

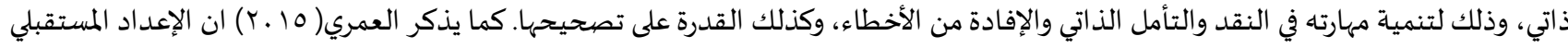

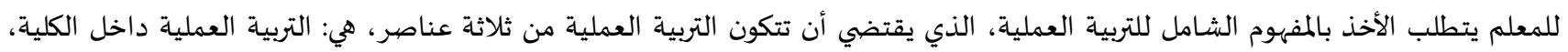
المنفصلة، و و المتصلة. وتضيف العمري (10 r ) أن برنامج التربية العملية يمر بالمراحل التالية: التهيئة المعرفية للطالب المعلم، مشاهدة أفلام الفيديو المسجلة، التدريس على المستوى المصغر. المشاهدات الحية داخل مدرسـة التدريب. والمشاركة في التدريس مع المعلم الأسـاسي بالفصل. التدريس الفعلي، والتقويم والنقد البناء للتدريس .

أخيرًا التقويم الشامل للتربية العملية الميدانية.

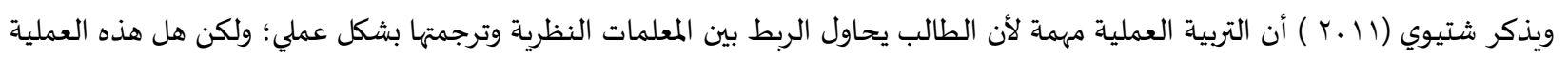
سهلة على طالب التربية العملية وليس من السهل ربط النظرية بالتطبيق؛ لأنه يفترض عند التخطيط لبرامج التربية العملية مراعاة الربط بين النظرية

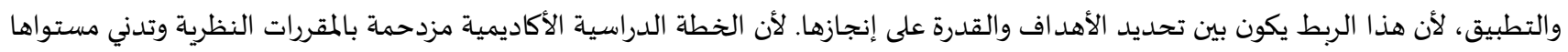

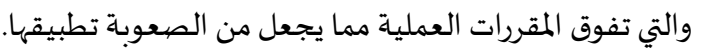

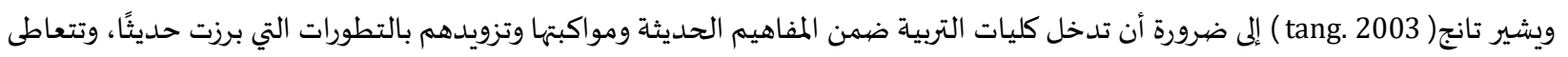
مع المستجدات التربوية ضمن المعطيات الرئيسة في برنامج التدريب الميداني . وفي المقابل تحظى برامج التدريب الميداني في الجامعات العربية باهتمام متزايد، وذلك من خلال تقويم ومراجعة الجامعات لبرامجها حول إعداد

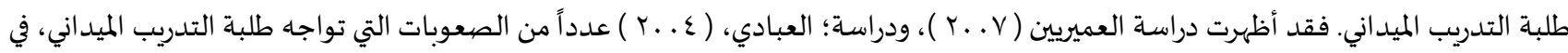
برنامج التربية العملية في الأردن، تتعلق بالإشراف على البرنامج، والمدرسة المتعاونة، والمعلم المتعاون .

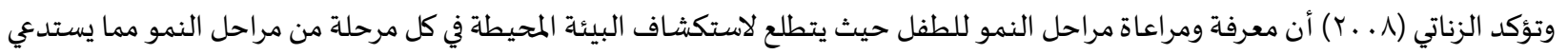

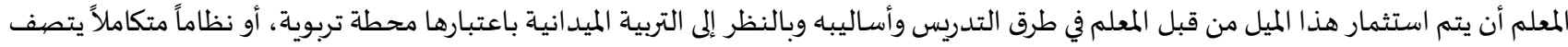

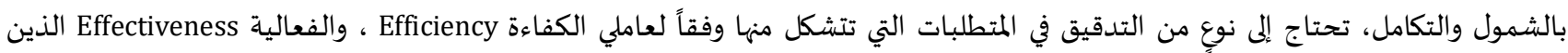
يشكلان ركني الجودة التربوية. . بالت يذكر العياصرة (ه . ب) حول أهمية التربية العملية للطالب فإن التربويين يكادون يجمعون على المكانة التي تحتلها التربية العملية واهميتها، ودورها في تزويد الطالب المعلم بالخبرة التدريسية، التي لا يصل إليها إلا من خلال ممارسة التدريس والتدريب على كفايات التخطيط وتنظيم الأنشطة

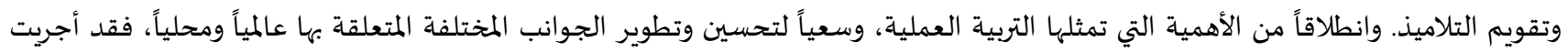

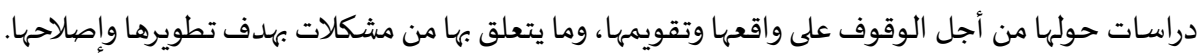
وقد أكد الزناتي (^ . . r ) على أهمية برامج إعداد المعلمين في الكليات الجامعية والمعاهد المتخصصية ويشير إلى جوهر هذا الإعداد ومخرجاته المتمثل في برنامج التدريب الميداني .

التدريب الميداني في التربية الخاصة:

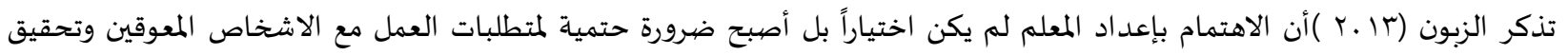

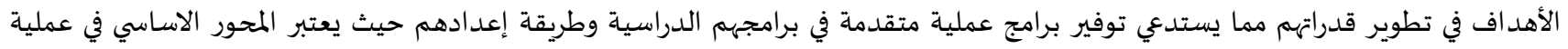

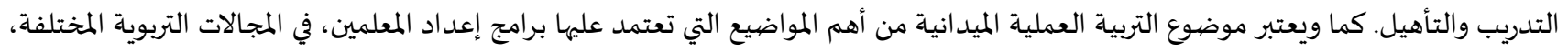

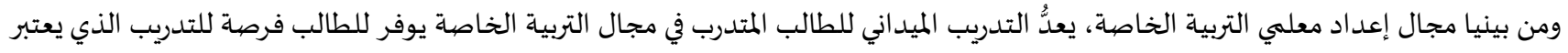
الاساس في مستقبلة المهني كذلك التعرف على الصعوبات التي توجها وكيفية التغلب عليها. إن التطور الملحوظ والمتسارع في مجال الاهتمام بالإعاقة في مختلف جوانها انعكس على الأشخاص ذوي الإعاقة وأسرهم بشكل إيجابي، وإن

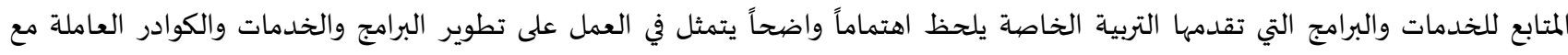


الاشخاص المعوقين، وجميعها تهدف للوصول إلى مستوى متقدم للخدمات والبرامج النوعية ، والتي تعتبر الاساس في تطوير قدرات الشخص المعوق لأفضل مستوى ممكن.

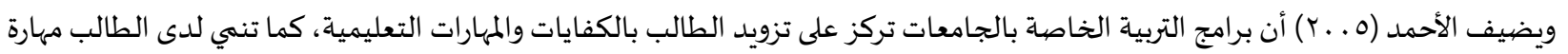

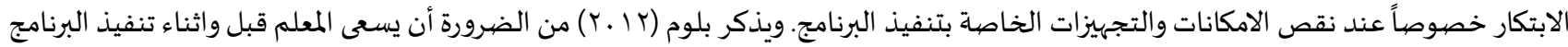

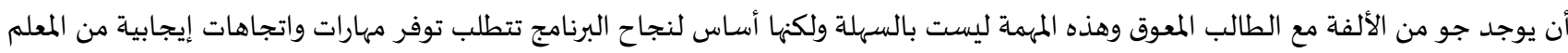

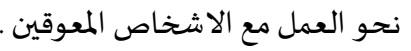

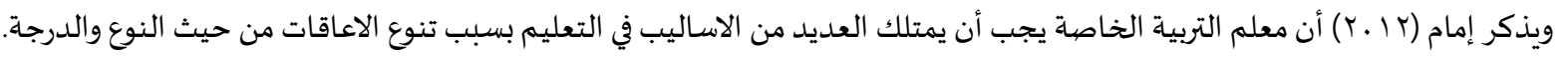

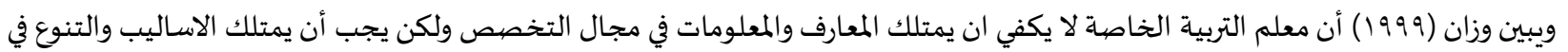

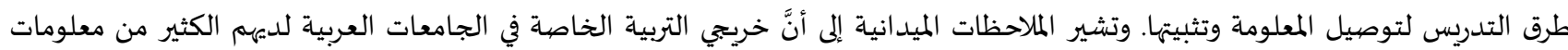

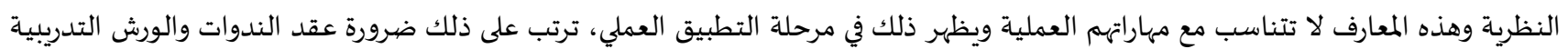

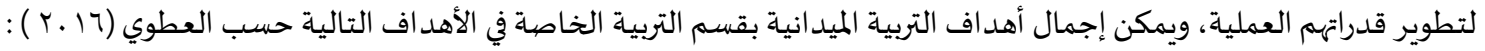
تعريف الطالب المعلم بالمهام المطلوبة منها أثناء التدريب الميداني في مؤسسات الترانية التربية الخاصية. تهيئة الفرص أمام الطالب المعلم لتحويل معارفه النظرية والمبادئ التربوية إلى مواقف فعلية تراعى الجودة المهنية. إتاحة الفرص أمام الطالب المعلم لفهم طبيعة العمل الذي سيقوم بمزاولتة بعد التخرج في مؤسسات التربية الخاصة.

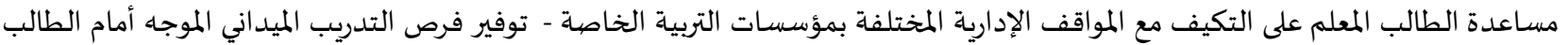
المعلم لتنمية مهاراته الإدارية المطلوبة.

تشجيع الطالب المعلم على مواجهة المشكلات التي تعترض طريقه أثناء التدربب الميداني، وحفزه على التفكير والتغلب عليها. منح الطالب المعلم الفرصة للتعرف إلى أنماط السموك- المختلفة لدى المتعاملين معاه، وطرق تفكيره وميولهم، لكي يكتسب بعض المهارات التي تمكناه من التعامل معهم. توفير فرصة أمام الطالب المعلم لمشاهدة بعض الدروس النموذجية، يقدمها معلمون من ذوي الخبرة، والمشهود لهم بالكفاءة في مجال التربية

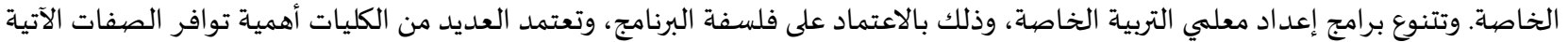

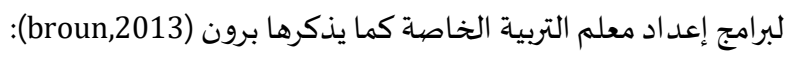

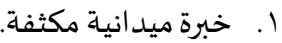
r. . تقييم فعالية تلك البرامج.

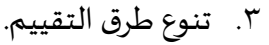

وتبنى مجلس الأطفال غير العاديين (CEC) نموذجاً لتطوير المههاج المستقبلي لإعداد معملي التربية الخاصة، ويشمل هذا النموذج المجالات الآتية كما ذكرها (saponar,2006) ديناميات المتعلمين.

ديناميت المهنة، وتشير إلى المعرفة بعلم التربية. ديناميت المجال، التي تشير إلى طلبة المدارس الذين يعانون من الإعاقات. تتنوع برامج إعداد معلمي التربية الخاصية، وذلك بالاعتماد على فلسفة البرنامج.

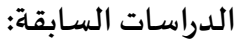

• أجرت وود (0 . . ( ) دراسة بعنوان "الكشف عن مساهمة برنامج التدريب الميداني في فهم الطلبة المعلمين لعمليةالتدريس"، حيث هدفت هذه الدراسـة إلى الكشف عن مساهمة برنامج التدريب الميداني في فهم الطلبة المعلمين لعمليةالتدريس، وقد تكونت عينة الدراسة من جميع طلبة

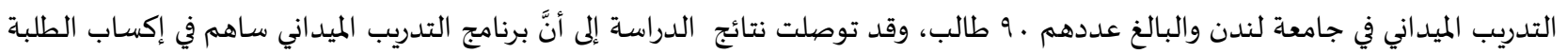
المعملين فهم أعمق للتدريس من خلال توظيفهم وربطهم للدراسات النظرية بالنواحي التطبيقية، كما وأشارت كذلك إلى أنَّ بعض المعلمين يفتقدون

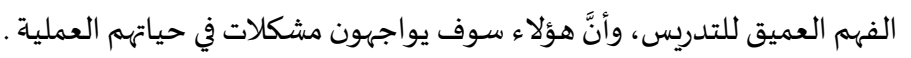

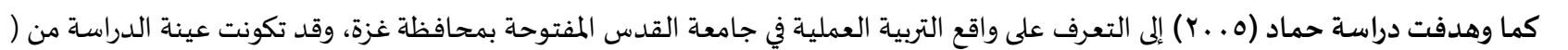

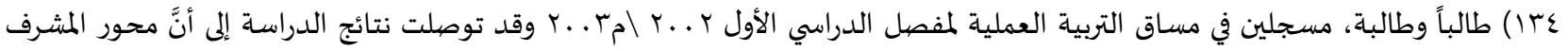


الأكاديمي احتل المرتبة الأولى في استجابات المفحوصين، بينما احتل المحور المتعلق بمدرسة التدربب المرتبة السابعة، وجاء من ضمن نتائج الدراسة اختلاف في أساليب التدريس التي يتبعها المعلم المتعاون في الفصل، عن التي يتم تدريسيا نظرياً للمدرسين.

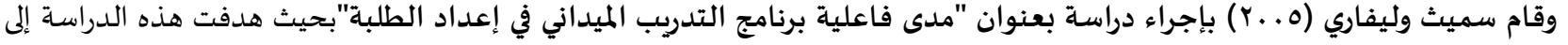

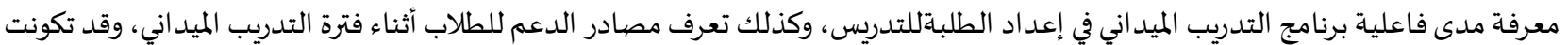

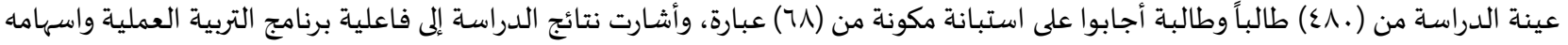

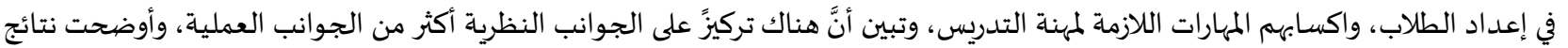

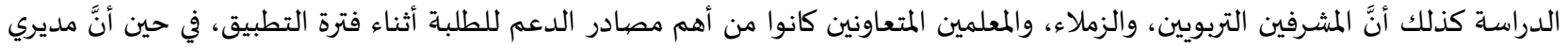

المدارس لم يقدموا الدعم اللازم للطلبة.

وأجرى واليلين وفانتون (Walelign \& Fantahun, 2006) دراسة بعنوان "مقترحات لتحسين التطبيق العملي لمعلمي الصفف المتدربين أثناء فترة

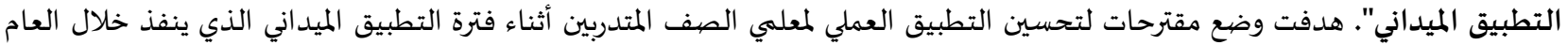

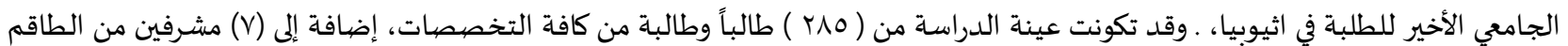

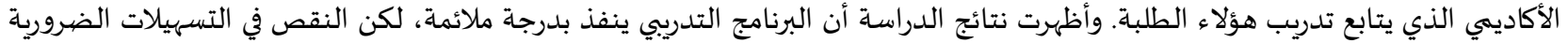

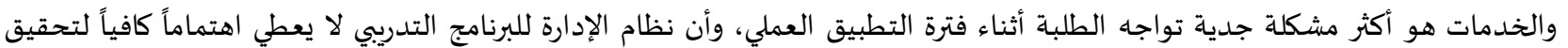

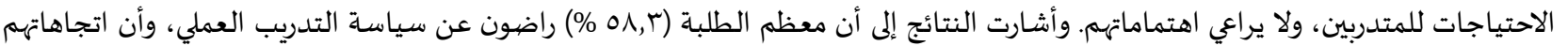

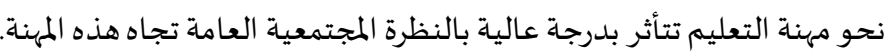

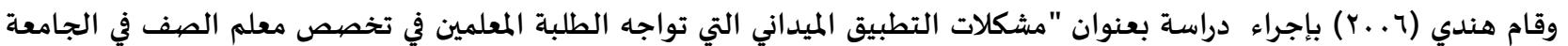

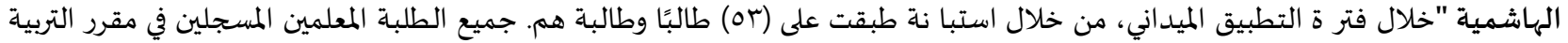

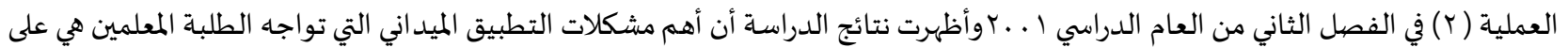

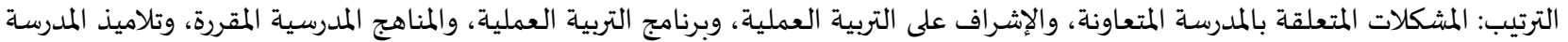

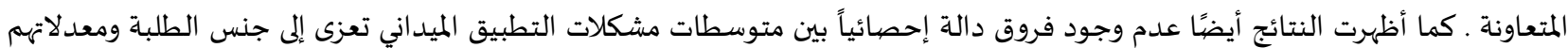
التراكمية.

كما وأجرى سفرجلو (seferoglu, 2006) دراسةً بعنوان "تقويم برنامج إعداد المعلمين في تركيا، من خلال استطلاع وجهة نظر الطلبة

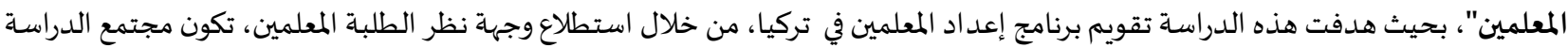

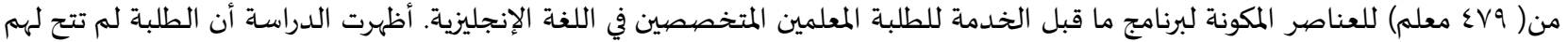

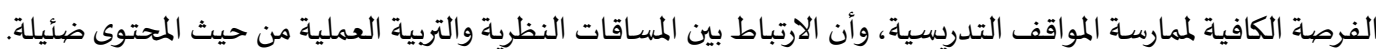

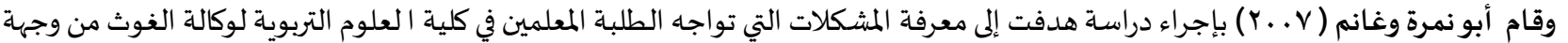

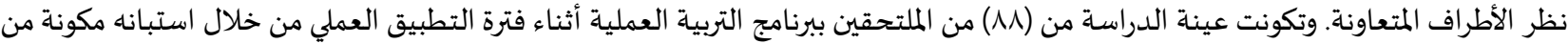

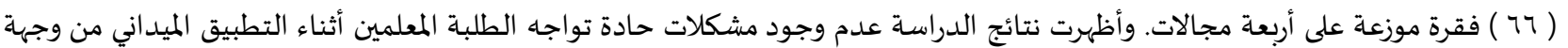

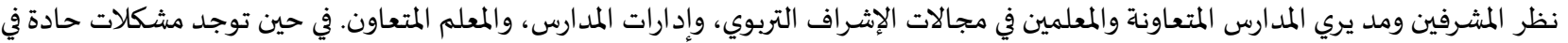

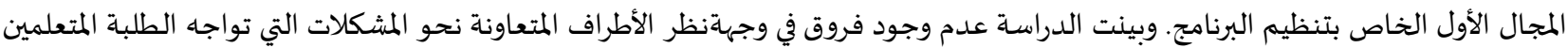
تعزى لمتغيرات الجنس، ومكان العمل، في حين توجد فروق ذات دلالة لمتغير الوظيفة ولصالح المششرفين على مجالات إدارة المدارس والمعادلم المتعاون إلى استقصاء المشكلات التي تواجه الطلبة. وحاولت دراسة خيرالهه (9 . ب) التعرف على دور التربية العملية في إكساب الطلاب المعلمين الكفايات التعليمية بكلية التربية بجامعة السودان،

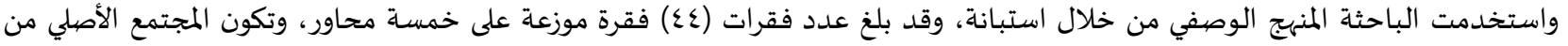

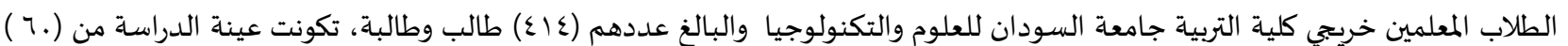

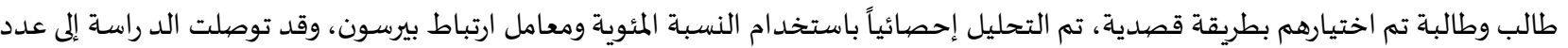

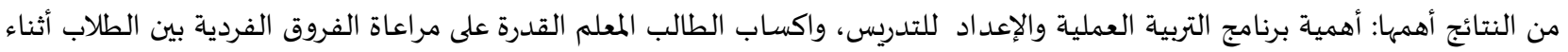
الدرس، وتدرببه على التصرف بكفاءة في المواقف التعلمية المختلفة، والتعاون والتفاعل بينه وبين الطالب. وأجرى شاهين ( • (Y. ) دراسة بعنوان "مشكلات التطبيق الميداني لمقرر التربية العملية في جامعة القدس المفتوحة من وجهة نظر الدارسين"

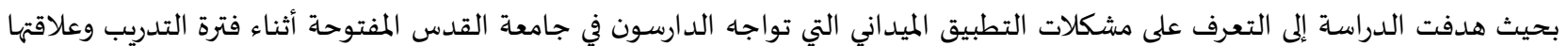


ببعض المتغيرات النوعية (الجنس، والتخصص )، والتفاعل بينهم وتحقيقاً لذلك طورت أداة للدراسة تضمنت ( .ع) فقرة موزعة على أربعة مجالات،

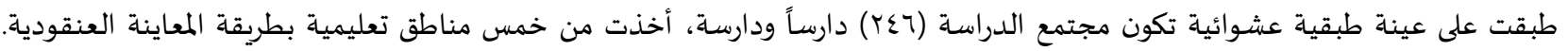

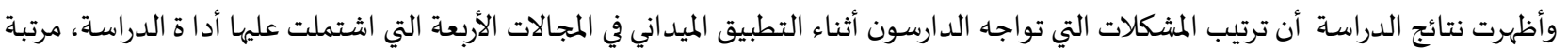
حسب أهميتها من وجهة نظر الدارسين كالآتي: مجال دور المشرف الأكاديمي، فمجال المدرسة المتعاونة، ثم مجال خطة التدريس، وأخيراً طلبة

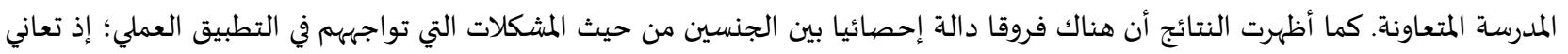

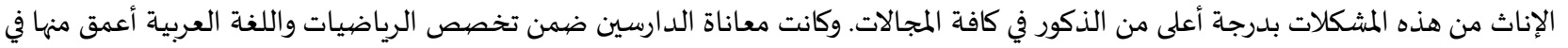

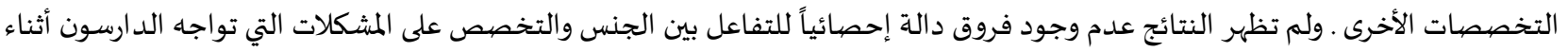
التطبيق الميداني.

وفي دراسـة الجعافرة والقطاونة (1 الـr)" و اقع التربية العملية في جامعة مؤتة من وجهة نظر الطلبة معلمي الصهف الخريجين"،هدفت الدراسة الحالية إلى تعرف واقع التربية العملية في جامعة مؤتة من وجهة نظر الطلبة معلمي الصف الخريجين، ولتحقيق هدف الدراسـة، قام الباحثان

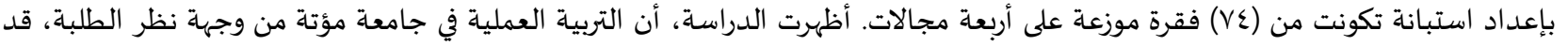

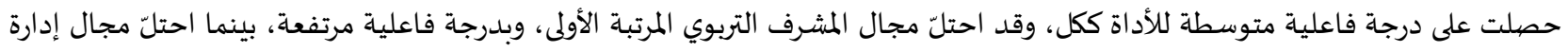
المدرسة المتعاونة المرتبة الأخيرة، وبدرجة فاعلية ضعيفة، ولم تظهر الدراسـة فروقاً ذات دلالة إحصائية من وجهة نظر الطلبة، حول حول واقع التربية

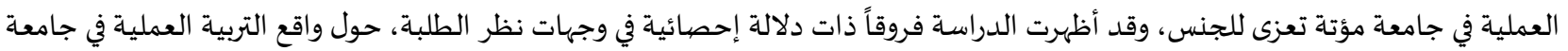

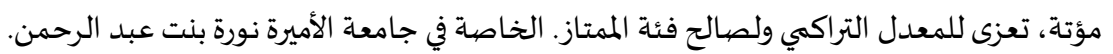
وأجرى العنزي (10 • (10) دراسة هدفت إلى التعرف على المشكلات التي تواجه طلبة التربية العملية في جامعة شقراء من وجهاة نظر الطلبة المعلمين أنفسهم، والتعرف على مدى اختلاف هذه المشكلات باختلاف التخصص والجنس والمعدل الاكاديمي، ولتحقيق هذا الهدف صهمم الباحث استبانة

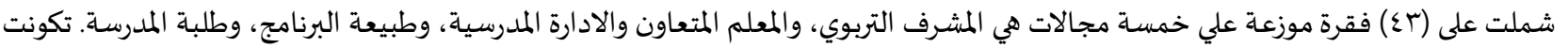

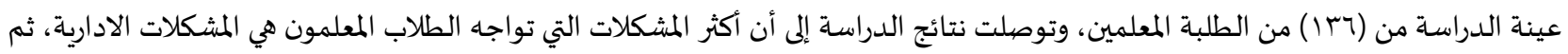

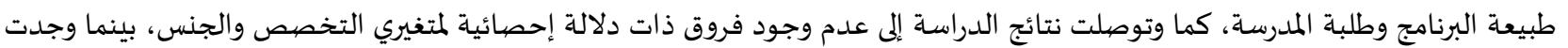

فروق ذات دلالة إحصائية لمتغير المعدل التراكمي.

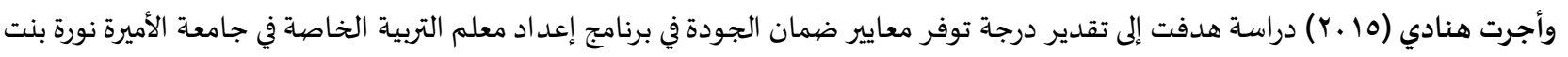
عبد الرحمن من وجهة نظر الطلبة المتوقع تخرجهم، إضافة إلى معرفة أثر المعدل التراكمي في معرفة هذه الدرجة. وقد اتبعت الدراسة المنهج

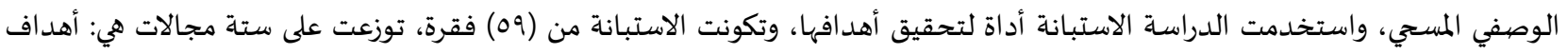

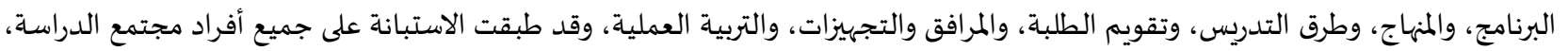

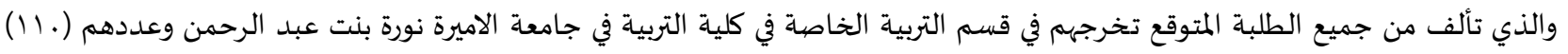

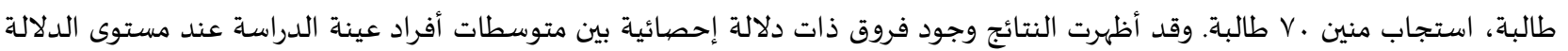
(م=0.05) حول تقديرهم لدرجة توفر معايير ضمان الجودة في برنامج إعداد معلم التربية الخاصة في جامعة الاميرة نورة بنت عبد الرحمن تعزى لمتغير المعدل التراكمي.

وفي المقابل أجرى العطوي (17 ـ ( ) دراسة هدفت إلى تقييم فاعلية برنامج التدريب الميداني من وجهة نظر طلبة قسم التربية الخاصية في جامعة

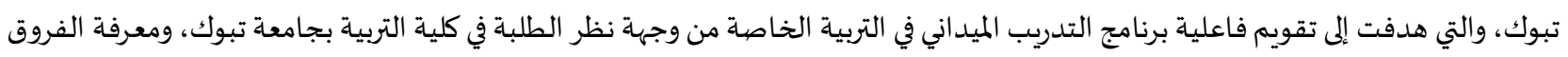

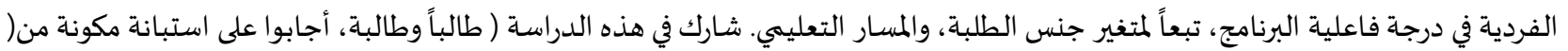

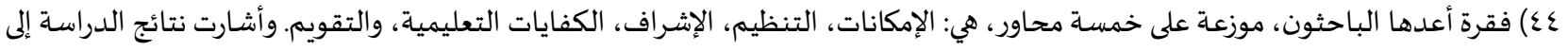

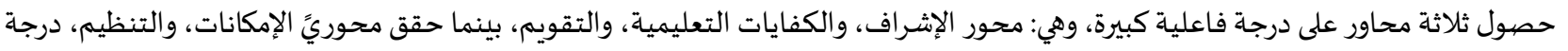
فاعلية متوسطة، وكما أشارت النتائج وجود فروق ذات دلالة إحصائية عند مستوى دلالة (0. . .) بين المتوسطات الحسابية، تعزى لمتغير المسار التعليمي؛ حيث يعتبر برنامج التدريب الميداني في قسم التربية الخاصة بجامعة تبوك أقل فاعلية بالنسبة لتخصصص التوحد، وكمات وكما أظهرت التهات النتائج وجود فروق ذات دلالة إحصائية عند مستوى دلالة (0 . . .) بين المتوسطات الحسابية في درجة فاعلية برنامج التدريب الميداني، تعزى لمتغير الجنس

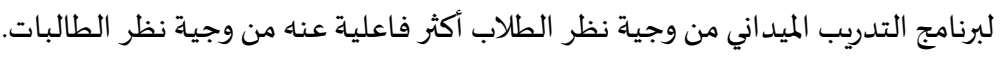




$$
\text { منهج الدراءاءة الدراسـة }
$$

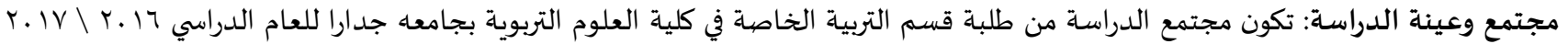

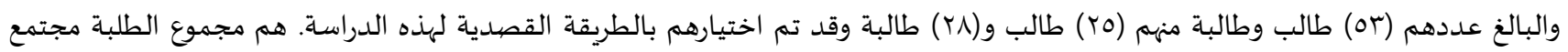

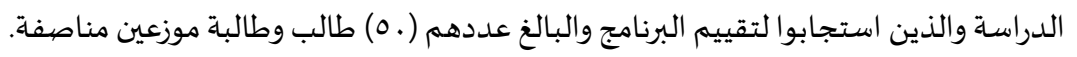

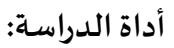

تم تصميم أداة الدراسة بعد الاطلاع على الأدب التربوي والدراسات السابقة ذات العلاقة، والدراسات التي تتشابه جزئياً مع الدراسة الحالية،

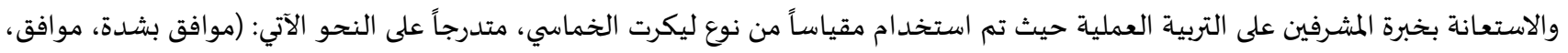

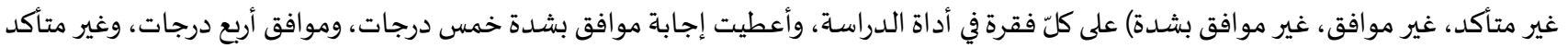

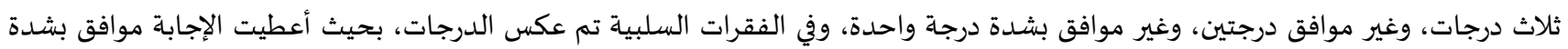

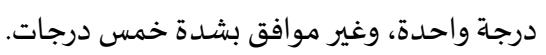

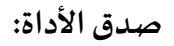

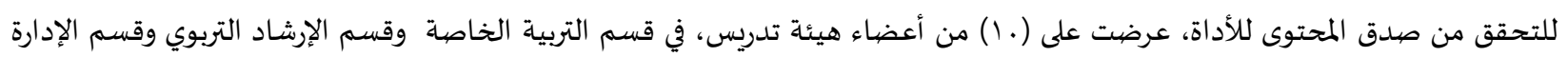

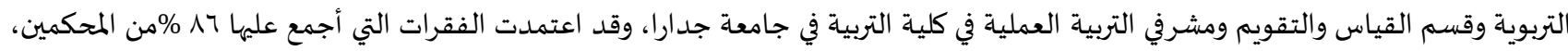

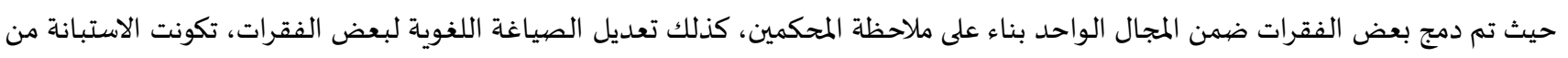

(ع \&) فقرة، تتضمن أربعة مجالات هي: الإشراف(1) (1) فقرة، الامكانات والتجهيزات (م) فقرات، التقييم (. ()، ومجال الكفايات التعليمية (10) فقرة.

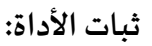

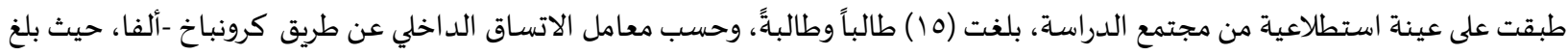

\begin{tabular}{|c|c|}
\hline معامل الثبات & المجال \\
\hline ., 10 & الإشراف \\
\hline 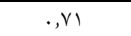 & الإمكانات \\
\hline . & التقييم \\
\hline 促 & الكفايات التعليمية \\
\hline .,$\Lambda$ & الاداة ككل \\
\hline
\end{tabular}

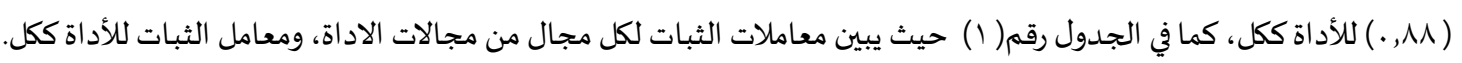

المعالجة الإحصائية:

Statistical package for ) للإجابة عن أسئلة الدراسة استخدم برنامج الرزم الإحصائية للعلوم الاجتماعية حيث طبقت المعالجات والطرائقة (Social Sciences

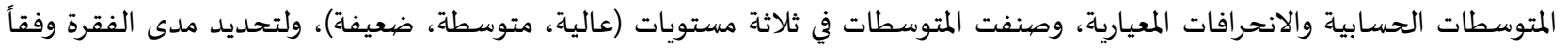

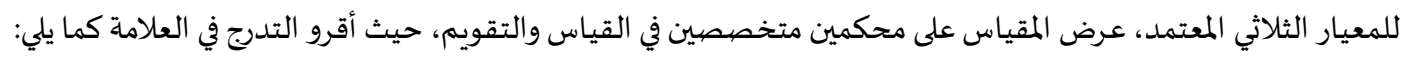

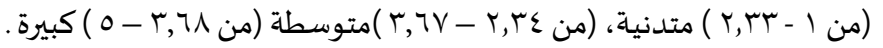

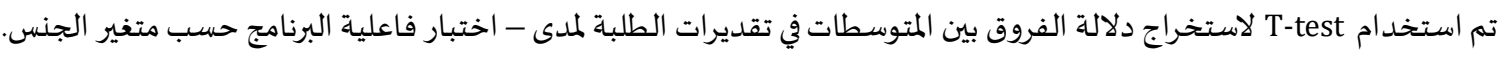
تحليل التباين الأحادي لفحص الفروق بين متوسطات تقديرات الطلبة، وفقاً لمتغير المعدل التراكمي.

النتائج ومناقشتها:

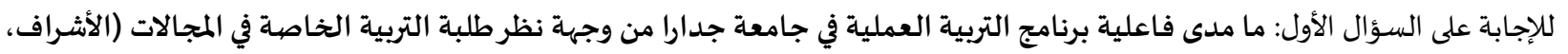

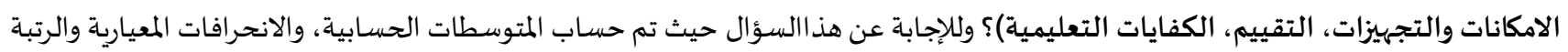

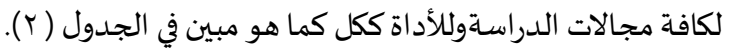




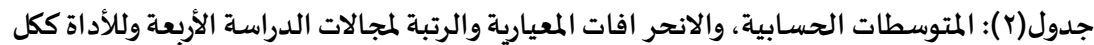

\begin{tabular}{|c|c|c|}
\hline الانحراف المعياري & الوسط الحسابي & المجال \\
\hline . & $r, 770$ & الإشراف 1 \\
\hline$r, 009$ &., $\mathrm{rY \Lambda}$ & الامكانات والتجهيزات r \\
\hline$r, r . q$ & . YqY & التقييم r \\
\hline$r, 017$ & . TTY & الكفايات التعليمية ع \\
\hline.,$\Gamma \leqslant 0$ & r,rro & الأداة ككل \\
\hline
\end{tabular}

يظهر الجدول(r) وجهة نظر الطلبة حول فاعلية التربية العملية لكافة المجالات جاءت متوسطة، حيث بلغ المتوسط الحسابي (ب (r , وبانحراف

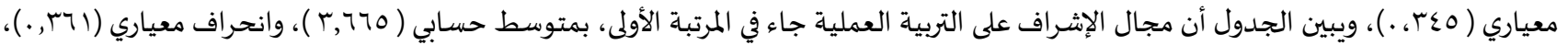

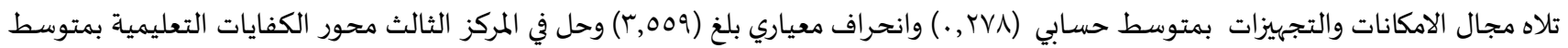

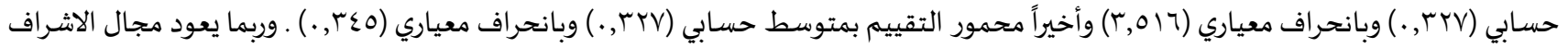
في الترتيب الاول لطبيعة التعامل التي يبنهيا المشرف مع الطلبة كذلك قد يكون الاختلاف في جنس المشرف حيث يختلف تعامل المشرف عن تعامل المشرف للطلاب والطالبات، كقد يعود مجال التقييم في المركز الاخير لعدم وجود معايير ثابتة لتقييم الطلبة. وتتفق نتيجة هذه الدراسـة مع نتائج

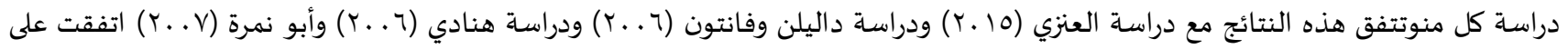

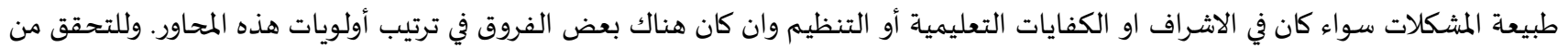

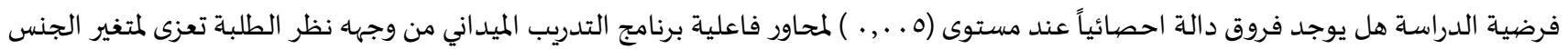

جدول (Y): المتوسطات الحسابية والانحر افات المعيارية لمحاور فاعلية التدريب الميداني وفقا لمتغير الجنس المبل

\begin{tabular}{|c|c|c|c|c|c|c|c|}
\hline مستوى الدلالة & درجة الحرية & قيمة F F & المعياري & المسابي & العدد & الجنس & المجال \\
\hline \multirow[t]{3}{*}{,,$\ldots 1$} & 1 & $9 Y, 7 \varepsilon$ & $0 \wedge, \wedge$ & $v \varepsilon, r$ & ro & ذكور & \multirow[t]{3}{*}{ الاشراف } \\
\hline & & & $\pi r, 1$ & va.r & ro & انثى ل انى & \\
\hline & & & $71, \varepsilon$ & $r, 7$ & 0 . & المجموع & \\
\hline \multirow[t]{3}{*}{,$\ldots$} & 1 & $77, \wedge 1$ & $70, Y$ & $r \eta, 1$ & ro & ذكور & \multirow[t]{3}{*}{ التقييم } \\
\hline & & & $V Y, T$ & $r 7,7$ & ro & انثى ل انى & \\
\hline & & & $v \varepsilon, r$ & $19, r$ & 0. & المجموع & \\
\hline \multirow[t]{3}{*}{., .1} & 1 & $\varepsilon 1, \Lambda r$ & $V Y, \varepsilon$ & $\varepsilon \wedge, \varepsilon$ & ro & ذكور & \multirow[t]{3}{*}{ الامكانات } \\
\hline & & & 77,1 & $\varepsilon \gamma, 0$ & ro & انثى & \\
\hline & & & 91,0 & $\varepsilon \varepsilon, r$ & 0. & المجموع & \\
\hline \multirow[t]{3}{*}{$\ldots$} & 1 & $\varepsilon, \lambda r$ & $T V, \Lambda$ & $r, T$ & ro & ذكور & \multirow[t]{3}{*}{ التقييم } \\
\hline & & & $T \Lambda, \vee$ & $r \varepsilon, 1$ & ro & انثى & \\
\hline & & & $\Lambda, 9$ & $r \cdot, \Lambda$ & 0. & المجموع & \\
\hline \multirow[t]{3}{*}{,$\ldots 1$} & 1 & $M, 7)$ & $V \varepsilon, r$ & $11, r$ & ro & ذكور & \multirow[t]{3}{*}{ محور المقياس الكلي } \\
\hline & & & $v \wedge, 1$ & $19, \Lambda$ & ro & انثى & \\
\hline & & & $\Lambda 7, r$ & $\mathrm{vA}, \mathrm{\eta}$ & 0. & المجموع & \\
\hline
\end{tabular}

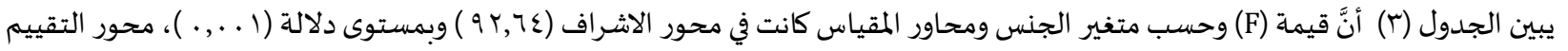

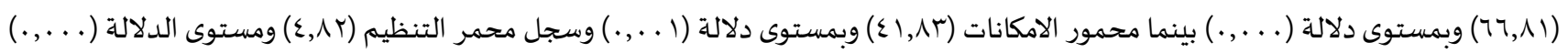

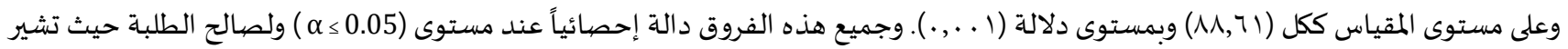

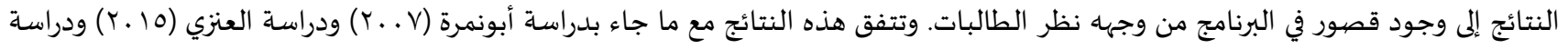

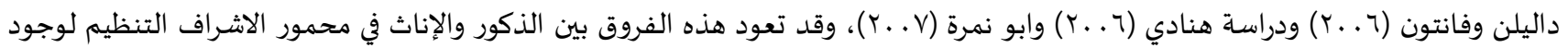
مشرفون من الذكور يجعل من الصعب تفهم متطلبات المعلمات مقارنة لتفهماه لمتطلبات الطلبة المعلمين الذكور، كما أن ربما يعود الاختلاف إلى طبيعة

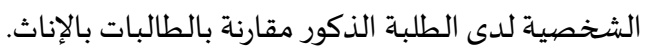


الاهتمام بمحتوى برامج التدريب الميداني لطلبة قسم التربية الخاصة في كلية التربية.

تصيميم نماذج موضوعية لتقييم أداء طلبة التدريب الميداني في التربية الخاصة.

تزويد المشرفين على التدريب الميداني بدورات تدريبية متقدمة في برامج الإشراف.

إجراء دراسات للتدريب الميداني في تخصصيات أخرى وتتناول بحث متغيرات أخرى في مجال التدريب الميد اني.

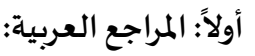

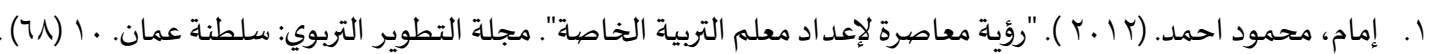

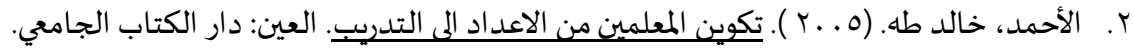

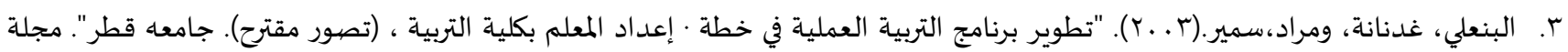

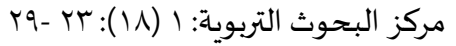

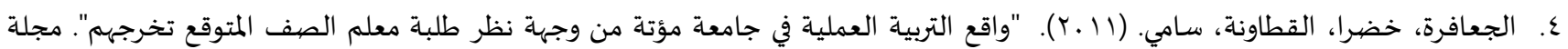
جامعة دمشق : Y ( )

0. حماد، شريف علي. ( 0. . ب). "واقع التربية العملية في مناطق جامعة القدس المفتوحة بمحافظات غزة من وجية نظر الدارسين ". مجلة الجامعة

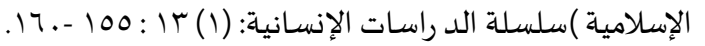

7. حمد، محمد مصطفى. (V . . r). "تصور مقترح لتطوير أداء مشرفي التربية العملية بكليات التربية بالجامعات الفلسطينية". رسالة ماجستير. جامعة الإسلامية. غزة. كلية التربية.

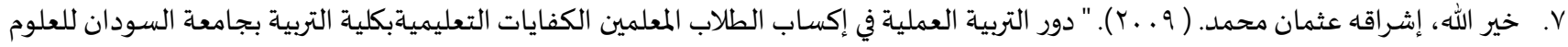

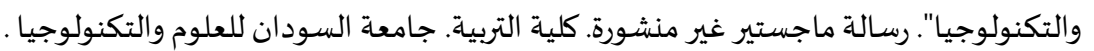

A. الدويغر، ليلى محمد.(Y . . Y). "تصور مقترح لتطوير برنامج الإشراف التربوي بكلية التربية في جامعة البحرين". مجلة العلوم التربوية والنفسية: . $1 .-\vee(1) r$

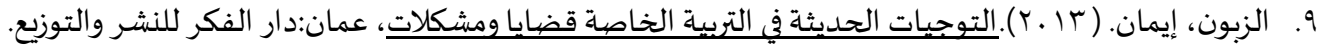

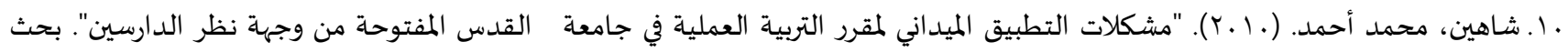

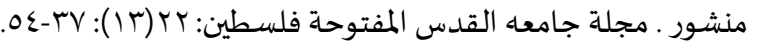

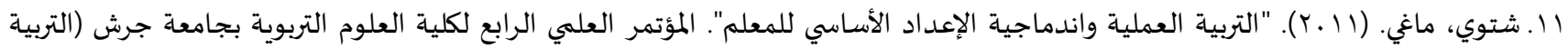

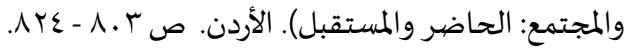
Y ا. العبادي، حامد مبارك.(ع . .ب). "مشكلات التربية العملية كما يراها الطلبة المعلمون نفي تخصص معلم الصف وعلاقتها باتجاهاتهم نحو مهنة

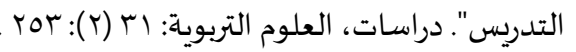

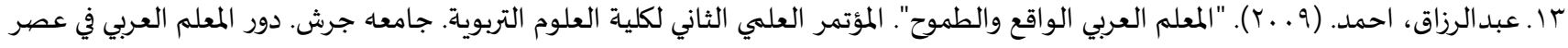
التدفق المعرفي. الاردن. ع ا ـ العطوي ، رويد ا. (7 ا ـ ب). "تقنيم فاعلية برنامج التدريب الميداني من وجهة نظر طلبة قسم التربية الخاصة في جامعة تبوك". قسم التربية الخاصة. كلية التربية. جامعة تبوك.

0 ا ـ العمري، مريم زيد. (0 ـr). "ميادين أين التربية العملية". مقالة علمية منشورة. مجلة معلم الغد. الرياض.

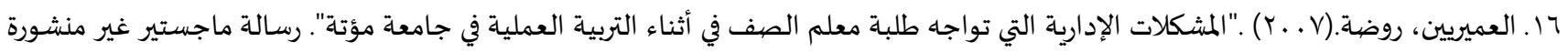
جامعة مؤتة. الكرك، الأردن. V ا العنزي، سعود فرحان. (10 ـ إ). "المشكلات التي تواجه طلبة التربية العملي من وجهاه نظر الطلبة المعلمين أنفسهم". بحث منشور. مجلة كلية التربية

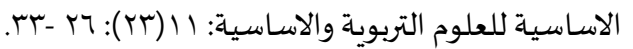
1/ ا العياصرة، محمد. ( 0 . . ץ). "تقويم طلبة معلمي التربية الإسلامية لبرنامج التربية العملية في كلية التربية بجامعة السلطان قابوس وفي كليات التربية

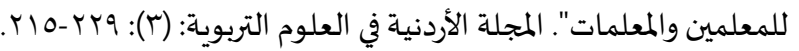


9 ا. قعدان، هنادي. (10 . r). "درجاء توفر معايير الجودة في برنامج إعداد معلم التربيه الخاصة في جامعت الأميرة نورة بنت عبد الرحمن". رسالة

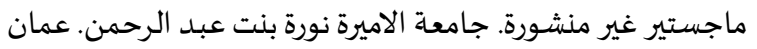

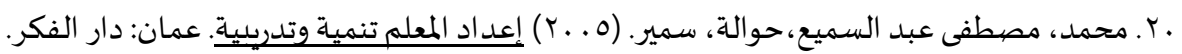

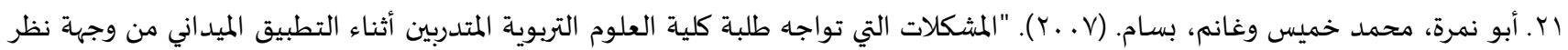

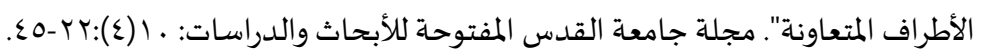

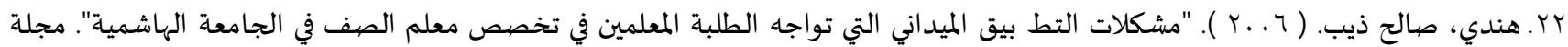

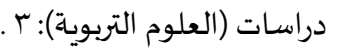

ثانياً: المراجع الأجنبية:

[1] Bauer A., Fordon A., Johnson L. \& Vincent N. (2006), "Teacher Education Reform Within University Special Education Programs". Focus on Exceptional Children. 38(5), https://doi.org/10.17161/fec.v38i5.6819.

[2] Callum C. (2005). "Critical Features of Special Education Teacher Preparation: A Comparison with General Teacher Education" The Journal of Special Education Vol. 38(4): 242-252, https://doi.org/10.1177/00224669050380040601.

[3] Seferoglue,G. (2006). "Teacher candidates Reflections on Some Components of Pre-service English Teacher Education Programme Turkey". Journal of Education for Teaching. 32(4): 369-378, https://doi.org/10.1080/02607470600981953.

[4] Smith K. \& Lev -Ari. L, (2005), "The place of the practicum in preservice teacher education: the voice of the students". Asia-Pacific Journal of Teacher Education. 33(3): 289-302.

[5] Walelign, T. \& Fantahun, M. (2008). “Assessment on problems of the new pre-service teachers training program in Jimma University". Ethiopian Journal of Education and science. 2(2), https://doi.org/10.4314/ejesc.v2i2.41980.

[6] Wood, K. (2000), "The experience of learning to teach: changing student teachers' ways of understanding teaching". Journal of Curriculum Studies 32(1): 75-93, https://doi.org/10.1080/002202700182862. 
المجلة الدولية للدراسـات التربوية والنفسية

International Journal of Educational \& Psychological Studies (EPS)

Journal Homepage: https://www.refaad.com/views/EPSR/Home.aspx

www.refaad.com

ISSN: 2520-4149 (Online) 2520-4130 (Print)

\title{
Evaluation of the effectiveness of the field training program in special education from the perspective of students at the university of Jadara
}

\author{
Ali Mohammad Al-Smadi \\ Department of Special Education, College of Educational Sciences, Jadara University, Jordan \\ alismadi_58@yahoo.com
}

Received Date : $13 / 12 / 2017$

Accepted Date : 25/4/2018

DOI : https://doi.org/DOI:10.31559/EPS2020.8.2.12

\begin{abstract}
The study aimed to evaluate the effectiveness of the field training program for graduate students majoring in special education from the viewpoint of themselves students, the study population of students from the Faculty of Special Education Department of Education is expected to graduate and studying the course of field training numbered (53) students, including (28)students, were evaluation of the program through a questionnaire consisting of (40) items, dealt with four supervision axes, evaluation, potential, educational competencies, and the study found that the axes of supervision and teaching competencies, and evaluation achieved the degree of great effectiveness compared to axes other, according to the sex variable showed the results of the study to There are differences statistically significant at the level of (0.05) for central supervision and evaluation While there is no significant differences between the central educational capabilities and competencies.
\end{abstract}

\section{Keywords: Field Training; Special Education; Students.}

\section{References:}

[1] Al'bady, Hamd Mbark.(2004). "Mshklat Altrbyh Al'mlyh Kma Yraha Altlbh Alm'lmwn ·Fy Tkhss M'lm Alsf W'laqtha Batjahathm Nhw Mhnh Altdrys". Drasat, Al'lwm Altrbwyh: 31 (2): 253.

[2] 'bdalrzaq, Ahmd. (2009). "Alm'lm Al'rby Alwaq' Waltmwh". Alm'tmr Al'lmy Althany Lklyh Al'lwm Altrbwyh. Jam't Jrsh. Dwr Alm'lm Al'rby Fy 'sr Altdfq Alm'rfy. Alardn.

[3] Al'mry, Mrym Zyd. (2015). "Myadyn Ayn Altrbyh Al'mlyh". Mqalh 'Imyh Mnshwrh. Mjlt M'lm Alghd. Alryad.

[4] Al'myryyn, Rwdh. (2007)."Almshklat Aledaryh Alty Twajh Tlbt M'lm Alsf Fy Athna' Altrbyh Al'mlyh Fy Jam't M'th". Rsalt Majstyr Ghyr Mnshwrh Jam't M'th. Alkrk, Alardn.

[5] Al'nzy, S'wd Frhan. (2015). "Almshklat Alty Twajh Tlbt Altrbyh Al'mly Mn Wjht Nzr Altlbh Alm'lmyn Anfshm". Bhth Mnshwr. Mjlt Klyt Altrbyh Alasasyh Ll'lwm Altrbwyh Walasasyh: 11(23): 26 -33.

[6] Al'twy, Rwyda. (2016). "Tqaym Fa'elyh Brnamj Altdryb Almydany Mn Wjht Nzr Tlbh Qsm Altrbyh Alkhash Fy Jam't Tbwk". Qsm Altrbyh Alkhash. Klyt Altrbyh. Jam't Tbwk.

[7] Al'yasrh, Mhmd. (2005). "Tqwym Tlbh M'lmy Altrbyh Aleslamyh Lbrnamj Altrbyh Al'mlyh Fy Klyh Altrbyh Bjam't alsltan Qabws Wfy Klyat Altrbyh Llm'lmyn Walm'lmat". Almjlh Alardnyh Fy Al'lwm Altrbwyh: (3): 229-215.

[8] Alahmd, Khald Th. (2005). Tkwyn Alm'Imyn Mn Ala'dad Ala Altdryb. Al'yn: Dar Alktab Aljam'y.

[9] Albn'ly, Ghdnanh, Wmrad,Smyr.(2003). "Ttwyr Brnamj Altrbyh Al'mlyh Fy Khth · E'dad Alm'lm Bklyh Altrbyh, (Tswr Mqtrh). Jam't Qtr". Mjlt Mrkz Albhwth Altrbwyh: 1 (18): 23 -29.

[10] Aldwyghr, Lyla Mhmd.(2002). "Tswr Mqtrh Lttwyr Brnamj Aleshraf Altrbwy Bklyh Altrbyh Fy Jam't Albhryn". Mjlt Al'lwm Altrbwyh Walnfsyh: 3(1): $71-80$

[11] Emam, Mhmwd Ahmd. (2012). "R'yh M'asrh Le'dad M'Im Altrbyh Alkhash". Mjlt Alttwyr Altrbwy: Sltnh 'Eman. 10(68).

[12] Hmd, Mhmd Mstfa. (2007). "Tswr Mqtrh Lttwyr Ada' Mshrfy Altrbyh Al'mlyh Bklyat Altrbyh Baljam'at Alflstynyh". Rsalt Majstyr. Jam't Aleslamyh. Ghzh. Klyt Altrbyh. 
[13] Hmad, Shryf 'ly. (2005). "Waq' Altrbyh Al'mlyh Fy Mnatq Jam't Alqds Almftwhh Bmhafzat Ghzh Mn Wjyt Nzr Aldarsyn ". Mjlh Aljam'h Aleslamyh) Slslt Ald Rasat Alensanyh: (1) 13: 155 -160.

[14] Hndy, Salh Dyb. (2006). "Mshklat Altt Byq Almydany Alty Twajh Altlbh Alm'lmyn Fy Tkhss M'lm Alsf Fy Aljam'h Alhashmyh". Mjlt Drasat (Al'lwm Altrbwyh): 3.

[15] Alj'afrh, Khdra, Alqtawnh, Samy. (2011). "Waq' Altrbyh Al'mlyh Fy Jam't M'th Mn Wjht Nzr Tlbt M'lm Alsf Almtwq' Tkhrjhm". Mjlt Jam't Dmshq: 27(3,4).

[16] Khyr Allh, Eshraqh 'Ethman Mhmd. (2009). " Dwr Altrbyh Al'mlyh Fy Eksab Altlab Alm'lmyn Alkfayat Alt'lymyhbklyh Altrbyh Bjam't Alswdan Ll'elwm Waltknwlwjya". Rsalt Majstyr Ghyr Mnshwrh. Klyt Altrbyh. Jam't Alswdan Ll'lwm Waltknwlwjya.

[17] Mhmd, Mstfa 'bd Alsmy', Hwalh, Smyr. (2005) 'edad Alm'lm Tnmyh Wtdrybyh. 'man: Dar Alfkr.

[18] Abw Nmrh, Mhmd Khmys Wghanm, Bsam. (2007). "Almshklat Alty Twajh Tlbh Klyt Al'lwm Altrbwyh Almtdrbyn Athna' Alttbyq Almydany Mn Wjht Nzr Alatraf Almt'awnh". Mjlt Jam't Alqds Almftwhh Llabhath Waldrasat: 10(4):22-45.

[19] Q'dan, Hnady. (2015). "Drjt Twfr M'ayyr Aljwdh Fy Brnamj 'dad M'lm Altrbyh Alkhash Fy Jam't Alamyrh Nwrh Bnt 'bd Alrhmn". Rsalt Majstyr Ghyr Mnshwrh. Jam't Alamyrh Nwrh Bnt 'bd Alrhmn. 'man.

[20] Shahyn, Mhmd Ahmd. (2010). "Mshklat Alttbyq Almydany Lmqrr Altrbyh Al'mlyh Fy Jam't Alqds Almftwhh Mn Wjht Nzr Aldarsyn". Bhth Mnshwr. Mjlt Jam't Alqds Almftwhh Flstyn: 22(13): 37-54.

[21] Shtwy, Maghy. (2011). "Altrbyh Al'mlyh Wandmajyh Ale'dad Alasasy Llm'elm". Alm'tmr Al'lmy Alrab' Lklyt Al'lwm Altrbwyh Bjam't Jrsh (Altrbyh Walmjtm': Alhadr Walmstqbl). Alardn. S 803 - 824.

[22] Alzbwn, Eyman. (2013). Altwjyat Alhdythh Fy Altrbyh Alkhash Qdaya Wmshklat, 'man: Dar Alfkr Llnshr Waltwzy'. 